\title{
Komparasi Keefektifan antara model Pembelajaran Kooperatif Tipe NHT dan tipe Snowball Throwing dalam Pembelajaran Geometri Analitik
}

\author{
${ }^{1}$ Mulyono Mulyono, ${ }^{2}$ Arie Anang Setyo \\ ${ }^{1,2}$ Jurusan Pendidikan Matematika, Fakultas Keguruan dan Ilmu \\ Pendidikan Universitas Muhammadiyah Sorong \\ e-mail: mulyonosmk@gmail.com, arieanangsetyo.ums@gmail.com
}

\begin{abstract}
Penelitian ini merupakan penelitian eskperimen yang bertujuan membandingkan dua model pembelajaran yaitu Model Pembelajaran Kooperatif tipe NHT dan Model pembelajaran Snowball Throwing serta untuk mengetahui yang lebih efektif untuk diterapkan pada mahasiswa Semester IV University Muhammadiyah Sorong. Subyek penelitian ini adalah mahasiswa kelas C dan D semester genap tahun pelajaran 2017/2018 yang terdiri dari 4 (empat) kelas. Teknik pengambilan sampel adalah menggunakan cluster random sampling. Hasil penelitian menunjukan bahwa: (1) Hasil belajar mahasiswa yang diajar dengan menggunakan model Pembelajaran Kooperatif tipe NHT mencapai ketuntasan belajar 96,7\%, mahasiswa memperoleh nilai minimal 70, nilai rata- rata 78,53 (2) Aktivitas mahasiswa dalam kategori baik yang diajar dengan menggunakan model kooperatif tipe NHT selama 4 kali pertemuan sudah dalam kategori baik, (3) respon mahasiswa terhadap model pembelajaran menunjukan respon yang positif (4) Hasil belajar mahasiswa yang diajar dengan menggunakan model Pembelajaran Kooperatif tipe Snowball Trhowing mencapai ketuntasan belajar 79,3\%, mahasiswa memperoleh nilai minimal 70, nilai rata- rata 71,69 (5) Aktivitas mahasiswa dalam kategori baik yang diajar dengan menggunakan model kooperatif tipe Snowball Trhowing selama 4 kali pertemuan sudah dalam kategori baik, (6) respon mahasiswa terhadap model pembelajaran menunjukan respon cenderung positif. Dengan demikian dapat disimpulakan bahwa model pembelajaran koopertif tipe NHT lebih efektif diterapakan pada mahasiswa semester IV Universitas Muhammadiyah Sorong.
\end{abstract}

Key Words: Comparasion, Effektiveness, Cooperative NHT and Snowball Trhowing

\section{PENDAHULUAN}

Geometri analitik merupakan mata kuliah yang merupakan bagian dari matematika mata kuliah ini cukup banyak menuntut pemahaman konsep dan intelektualitas yang relatif tinggi sehingga menyelesaikan soal yang berkaitan dengan geometri analitik mahasiswa masih banyak mengalami kesulitan. Beberapa mahasiswa menganggap mata kuliah geometri analitik mata kuliah yang rumit, dalam peneltianya Imswatama, Aristya dkk (2016) Terdapat beberapa kesalahan yang dilakukan mahasiswa dalam mengerjakan soal geometri analitik materi garis dan lingkaran diantaranya (1) kesalahan konsep yaitu kesalahan yang dilakukan mahasiswa karena tidak memahami konsep yang baik, (2) kesalahan startegi yaitu kesalahan yang terjadi karena mahasiswa memilih cara mengerjakan 
yang tida tepat, (3) kesalahan hitung yaitu, kesalahan dalam melakukan operasi matematika. (4) kesalahan sistematik, yaitu kesalahan yang berkenaan dengan pemilihan yang salah atas teknik ekstrapolasi. Sebagian mahasiswa menyampaikan juga model pembelajaran yang diterapkan dosen model pembelajaran konvensional sehingga mahasiswa mengalami kesulitan dalam pembelajaran khususnya untuk dapat diterima dikalangan mahasiswa pada mata kuliah geometri analitik. Oleh karena itu peneliti menerapkan model pembelajaran kooperatif tipe NHT dan Snowball Throwing, yang selanjutnya akan diketahui mana yang lebih efektif diterapkan dalam proses pembelajaran di dalam kelas.

Penerapan model pembelajaran merupakan strategi peneliti untuk menyelesaikan persoalan yang di alami oleh mahasiswa khusunya dalam mata kuliah geometri analitik, model pembelajaran yang diterapkan didaerah - daerah maju mungkin sudah tidak baru lagi namun pada penelitian ini model yang digunakan sangat dianggap baru karena di papua barat belum pernah ada peneliti sebelumnya yang melakukan eksperimen menggunakan kedua model tersebut khusunya di kampus Universitas muhammadiyah Sorong. Olehnya itu peneliti optimis pada peneltian ini akan diketahui model pembelajaran yang baru dan efektif untuk diterapkan khusunya pada mata kuliah geometri analitik.

Model pembelajaran menurut Trianto (2010:53) adalah "Kerangka konseptual yang meluksikan prosedur sitematik dalam mengorganisasikan pengalaman belajar untuk mencapai tujuan belajar" Sedangkan model- model pembelajaran sendiri biasa disusun berdasarkan berbagai prinsip atau teori pengetahuan. Para ahli menyususn model pembelajaran berdasarkan prinsip - prinsip pembelajaran, teori - teori psikologis, analisis system, atau teori - teori lain yang mendukung Joyce \& weil dalam Rusman (2014:132). Joyce \& weil berpendapat bahwa model pembelajaran adalah suatu rencana atau pola yang dapat digunakan untuk membentuk kurikulum (rencana pembelajaran jangka panjang), merancang bahan - bahan pembelajaran dan membimbing di kelas atau yang lain.

Adapun beberapa penelitian terdahulu diantaranya: a) Miftakhus Sholikhah dan Hartono (2015) Dari hasil peneltiannya menyatakan problem based learning dengan setting model pembelajaran kooperatif tipe Nambered Head Together (PBL-NHT) efektif di tinjau dari kemampuan berpikir kritis dan disposisi matematis, kelemahan tidak efektif ditinjau dari prestasi belajar matematika siswa dan pada penelitian ini belum mampu menanamkan konsep matematika dengan baik; b) Putu Prema Santi, Dkk (2016) Dari hasil penelitianya menyatakan terdapat perbedaan hasil belajar antara kelompok siswa yang belajar dengan menggunakan model pembelajaran group investigation, snowball throwing dan 
konvensional penerapan model pembelajaran group investigation lebih baik dibandingkan dengan snowball throwing. Kelemahanya pada peneltian ini siswa belum mampu secara efektif dalam membuat pertanyaan untuk diberikan ke kelompok lainya; c) Arianto. Riki Devid, dan Rakhmawati.Lusia (2013) Dengan penerapan pembelajaran kooperatif tipe NHT berpengaruh positif terhadap hasil belajar siswa pada standar kompetensi penerapan dasar - dasar teknik digital di smk negeri 2 lamongan dan dengan menggunakan model pembelajaran numbered head together materi yang disampaikan lebih mudah dipahami hal ini menunjukan bahwa bannyak siswa yang merasa puas dan senang dengan apa yang diperoleh dari proses pembelajaran kooperatif tipe NHT. Kelemahanya pada penelitian ini siswa belum mampu dan efektif dalam membuat rangkuman; d) Putra. Danang Pradana dan Rakhmawati,.Lusia (2013) Menyimpulkan bahwasanya siswa yang diberi teori dengan model pembelajaran kooperatif tipe NHT menjadi lebih kreatif, dapat memahami,menjawab serta termotivasi untuk menganalisis permasalahan yang ada. Kelemahanya siswa yang belum mendapatkan nomor untuk mengerjakan/menjawab pertanyaan cenderung pasif.

Berdasarkan hasil beberapa penelitian diatas maka peneliti akan melaksanakan penelitian tentang komparasi keefektifan antara model pemebelajaran kooperatif tipe NHT dan tipe Snowball Trhowing dalam pemebelajaran geometri analitik pelaksanaan penelitian akan dilaksanakan di universitas muhammadiyah sorong.

Sehingga melalui penerapan model pembelajaran kooperatif tipe NHT dan Snowball Trhowing pada pembelajaran di kelas diharapakan mampu meningkatkan keefektifan dan hasil belajar mahasiswa dan diharapakan dosen mampu merencakanan pemebelajaran sedemikian rupa, sehingga pembelajaran berjalan sesuai dengan harapan. Model pembelajaran tersebut melibatkan aktivitas seluruh mahasiswa tanpa ada perbedaan status, melibatkan peran mahasiswa sebagai tutor sebaya dan mengandung unsur permainan, aktivitas mahasiswa dirancang sedemikian sehingga memungkinkan mahasiswa dapat belajar lebih rileks/santai, disamping menumbuhkan rasa tanggung jawab, kerja sama, persaingan sehat, dan keterlibatan belajar. Dengan demikian pembelajaran ini mampu mengefektifkan dan meningkatkan hasil belajar mahasiswa.

\section{Rumusan Masalah}

Berdasarkan latar belakang yang dikemukakan di atas, maka rumusan masalah sebagai berikut: (1) bagaimana keefektifan belajar mahasiswa semester IV kelas C program studi pendidikan matematika Universitas Muhammadiyah Sorong dengan menggunakan model pembelajaran kooperatif 
tipe NHT ?; (2) bagaimana keefektifan belajar mahasiswa semester IV kelas D program studi pendidikan matematika Universitas Muhammadiyah Sorong dengan menggunakan model pembelajaran kooperatif tipe Snowball Throwing ?; (3) apakah ada perbedaan keefektifan belajar mahasiswa semester IV kelas C program studi pendidikan matematika Universitas Muhammadiyah Sorong dan mahasiswa semester IV kelas D program studi pendidikan matematika Universitas Muhammadiyah Sorong, dengan menggunakan model pembelajaran kooperatif tipe NHT dan kooperatif tipe Snowball Throwing?

\section{METODE PENELITIAN}

Desain penelitian yang digunakan adalah two comparative groups pretest posttest design. Subyek dalam peneltian ini adalah seluruh mahasiswa semester IV universitas Muhammadiyah sorong tahun pelajaran 2017/2018 yang terdiri dari 4 kelas dan berjumlah 150 mahasiswa. Instrumen yang digunakan untuk mengumpulkan data adalah sebagai berikut: a) lembar observasi keterlaksanaan pembelajaran; b) lembar Observasi Aktivitas Mahasiswa; c) angket Respons Mahasiswa; d) tes Hasil Belajar 


\section{HASIL PENELITIAN}

Deskriptif Hasil Perbandingan Penerapkan Pembelajaran Dengan Model Pembelajaran Kooperatif Tipe NHT dan ST.

a. Perbandingan pada hasil analisis deskriptif

b. Indikator keefektifan yang dibandingkan pada analisis deskriptif adalah hasil belajar mahasiswa, aktivitas mahasiswa dalam pembelajaran dan respon mahasiswa terhadap perangkat pembelajaran dan pembelajarannya.

1) Hasil belajar mahasiswa

Perbandingan skor hasil belajar mahasiswa ditentukan dengan membandingkan rata-rata posttest, gain ternormalisasi dan persentase ketuntasan secara klasikal sebagai berikut.

Tabel Perbandingan Skor Aktivitas mahasiswa dalam Pembelajaran

\begin{tabular}{ccc}
\hline Kelas & Skor Rata-rata Total & Kategori \\
\hline Eksperimen I & 3,1 & Baik \\
Eksperimen II & 2.9 & Baik
\end{tabular}

Berdasarkan tabel diatas dapat disimpulkan bahwa aktivitas mahasiswa pada kelas eksperimen I yang diajar dengan model pembelajaran kooperatif tipe NHT labih baik daripada aktivitas mahasiswa pada kelas eksperimen II yang diajar dengan model kooperatif tipe ST yang ditandai dengan skor rata-rata total aktivitas mahasiswa pada kelas eksperimen I lebih besar daripada kelas ekperimen II yakni 3,1 > 2,9.

\section{Respons mahasiswa}

Perbandingan respons mahasiswa ditentukan berdasarkan skor rata-rata respons mahasiswa pada masing-masing kelas sebagaimana tampak pada tabel berikut.

Tabel 5.19. Perbandingan Skor Respons mahasiswa Terhadap Perangkat dan Pembelajaran

\begin{tabular}{llcl}
\hline Kelas & \multicolumn{2}{c}{ Skor Rata-rata Total } & Kategori \\
\hline Eksprerimen I & & 3,8 & Positif \\
Eksperimen II & & 3,2 & Positif \\
\hline Kelas & $\begin{array}{l}\text { Rata-rata } \\
\text { Postest }\end{array}$ & Gain & KK(\%) \\
\hline
\end{tabular}




\begin{tabular}{cccc}
\hline Eksperimen I & 78,53 & 0,73 & 96.7 \\
Eksperimen II & 71,69 & 0,63 & 79.3 \\
\hline
\end{tabular}

Berdasarkan tabel diatas dapat disimpulkan bahwa respon mahasiswa pada kelas ekspreimen I yang diajar dengan menggunakana model kooperatif tipe NHT labih baik dari pada respons mahasiswa pada kelas ekspreimen II yang diajar dengan model kooperatif tipe ST yang ditandai dengan skor rata-rata total respons mahasiswa pada kelas ekspreimen I lebih besar dari pada skor rata-rata respons mahasiswa pada kelas eksperimen II yakni 3,8 > 3,2.

\section{Perbandingan pada hasil analisis inferensial}

Berdasarkan hasil uji hipotesis adalah: a) rata- rata gain hasil belajar siswa kelas NHT dan ST Setelah dianalisis secara inferensial menunjukan (Ho) ditolak dan (H1) diterima ini berarti peningkatan hasil belajar dengan model pembelajaran kooperatif tipe NHT lebih baik di banding dengan peningkatan hasil pembelajaran yang diajar dengan model pembelajaran ST; b) rata- rata hasil belajar siswa kelas NHT dan ST. Setelah dianalisis secara inferensial menunjukan (Ho) ditolak dan (H1) diterima ini berarti rata-rata hasil belajar dengan model pembelajaran kooperatif tipe NHT lebih baik di banding dengan rata-rata hasil pembelajaran yang diajar dengan model pembelajaran ST; c)etuntasan belajar secara klasikal menunjukan (Ho) ditolak dan (H1) diterima untuk Model pembelajaran NHT dan (Ho) diterima dan (H1) ditolak ini berarti ketuntasan klasikal hasil belajar dengan model pembelajaran kooperatif tipe NHT signifikan dan ketuntasan klasikal hasil belajar dengan model pembelajaran kooperatif tipe ST tidak signifikan; d) Uji Perbedaan peningkatana hasil belajar siswa kelas NHT dan ST.

Dari hasil uji-t untuk mengetahui apakah ada perbedaan antara hasil belajar geometri analitik mahasiswa pada kelas eksperimen I, dan kelas eksperimen II. Setelah dilakukan pengolahan data, tampilan output dapat dilihat pada lampiran 18. Analisis yang di gunakan uji independent samples test pada lampiran 18 diperoleh nilai sig. (2-tailed) $=0,014$ yang kurang dari nilai alpha $=0,05$ ini berarti hipotesis $\left(\mathrm{H}_{1}\right)$ yang dirumuskan pada bab II diterima yaitu ada perbedaan peningkatan yang signifikan hasil belajar siswa pada pembelajaran kooperatif antara tipe NHT, dan pembelajaran kooperatif tipe Snowball Trhowing. 
Berdasarkan Uji homogenitas varians, dari hasil analisis SPSS, data yang diuji adalah data nilai gain dari ekperimen 1 dan ekperimen II dari pengujian tersebut terlihat pada lampiran 18 nilai $\mathrm{P}>\alpha$ yang menunjukan hasil 0.189 ini berarti data yang di pake merupakan data yang memiliki varians yang sama atau homogen.

\section{SIMPULAN}

Berdasarkan hasil penelitian dan pembahasan penulis menarik kesimpulan pada penelitian ini adalah sebagai berikut: 1) berdasarkan keriteria keefektifan yang telah ditetapkan dapat dikatakan bahwa pada mahasiswa kelas C Semester IV Prodi Pendidikan matematika Universitas Muhammadiyah Sorong, dengan menggunakan model pembelajaran kooperatif tipe NHT dapat dikatakan efektif; 2) berdasarkan keriteria keefektifan yang telah ditetapkan dapat dikatakan bahwa pada mahasiswa kelas D Semester IV Prodi Pendidikan matematika Universitas Muhammadiyah Sorong, dengan menggunakan model pembelajaran kooperatif tipe ST dapat dikatakan cukup efektif; 3) berdasarkan keriteria keefektifan yang telah ditetapkan dapat dikatakan bahwa Penerapan pembelajaran pada mahasiswa kelas C semester IV Prodi Matematika Universitas Muhammadiyah sorong dengan menggunakan model pembelajaran kooperatif tipe NHT lebih efektif dibandingkan dengan mahasiswa kelas D semester IV prodi matematika Universitas Muhammadiyah sorong dengan menggunakan model pembelajaran kooperatif tipe ST.

\section{SARAN}

1. Bagi Dosen matematika di UMS Sorong disarankan memahami dan menggunakan beberapa model atau metode pembelajaran yang tepat dan bervariasi yang sesuai dengan materi ajar guna menciptakan mahasiswa yang aktif dan berprestasi serta tidak membosankan.

2. Penelitian ini mengungkapkan ada tidaknya perbedaan keefektifan pembelajaran geometri analitik dengan model pembelajaran kooperatif tipe NHT, dan pembelajaran koopertif tipe ST. Apabila hasil belajar mahsiswa yang akan dijadikan sebagai patokan pada penelitian ini, maka yang paling unggul adalah model pembelajaran kooperatif tipe NHT. dan bagi dosen matematika yang ingin menerapkan salah satu dari kedua model ini pada materi geometri analitik maka penulis menyarankan untuk menggunakan pembelajaran kooperatif tipe NHT, 
3. Kepada para peneliti dibidang pendidikan matematika agar kiranya dapat mempertimbangkan untuk melaksanakan penelitian tentang komparasi keefektifan model pembelajaran kooperatif tipe NHT dan pembelajaran koopetif tipe ST ini lebih lanjut, dengan menyediakan waktu yang banyak lagi agar pelaksanaannya lebih efektif.

4. Penelitian komparasi ini hendaknya dilakukan berulang - ulang dengan pokok bahasan yang berbeda - beda dan pada tingkat pendidikan yang berbeda agar dapat diketahui model yang cocok untuk digunakan dalam mengajarkan materi matematika,

5. Penelitian ini masih memiliki banyak keterbatasan sehingga bagi para peneliti yang hendak melakukan penelitian yang sama hendaknya mencermati keterbatasan tersebut untuk dilaksanakan yang lebih sempurna.

\section{DAFTAR PUSTAKA}

Arends, Richard L. 2008. Learning To Teach buku satu. Yogyakarta : Pustaka Pelajar.

Darmadi Hamid.2011. Metode penelitian pendidikan. cet2.Alfabeta. Bandung

Imswatama, Aristya dan Muhasanah Nur'ani.2016. Analisis Kesalahan Mahasiswa dalam Menyelesaikan Soal Geometri Analitik Bidang Materi Garis dan Ligkaran. Suska journal of mathematics Educatin 2(1)2016.

Susanto, Joko.2012. Pengembangan perangkat pembelajaran berbasis lesson study dengan kooperatif tipe numbered heads together untuk meningkatkan aktifitas dan hasil belajar IPA di Sd. Journal unnes 2(1) 2012

Kurniasih dan Sani.2015. Ragam pengembangan Model pembelajaran Untuk Peningkatan Profisionlitas Guru. Kata Pena. Yogyakarta.

Lestari, Karunia Eka dan Yudhanegara, Muhammad Ridan,2015. Penelitian Pendidikan Matematika. PT Refika Aditama.Bandung

Rusman,2014. Model-model Pembelajaran mengembagkan Profesionlisme Guru.Cet V Jakarat: PT. Rajagrafindo Persada.

Rasyid, Muhaedah dan Side Sumiati, 2011. Pengaruh Penerapan Model Pembelajaran Snowball Throwing terhadap hasil belajar Siswa Kelas X SMAN I Bajeng Kab. Gowa. Jurnal Chemica 12(2) desember 2011,69-76

Trianto,2010. Model Pembelajaran terpadu, Jakarta : Bumi aksara.

Trianto, 2013. Mendesain model Pembelajaran Inovatif Progresif. Jakarta :

Kencana Prenada media Group.

Warsita.Bambang,2008.Teknologi Pembelajaran Landasan dan Aplikasinya, Jakarta: Rineka Cipta.

Sholikhah.M dan Hartono,2015. Perbandingan Keefektifan antara Problem Based Learning Setting Nambered Head Together dan Jigsaw.Jurnal Riset Pendidikan Matematika 2(1) 63 -77

Putu Yuni Prema Santi, Ketut Agustini,Dewa Gede Hendra Divayana.2016. Studi Komparatif Penggunaan Model Pembelajaran Group Investigation dan snowball Throwing terhadap 
Motivasi dan Hasil Belajar pada mata pelajaran TIK siswa kelas $X$ SMA LaboratoriumUndksha. Kumpulan Artikel mahasiswa pendidikan Teknik Informatika 5(2).

Arianto.Riki Devid, dan Rakhmawati.Lusia.2013. Perbandingan Model Pembelajaran kooperatif tipe numbered Heads Together(THT) dengan tipe think Pair Share (TPS) terhadap hasil Belajar siswa pada standar kompetensi menerapkan dasar - dasar teknik digital di SMK Negeri 2 Lamongan. Jurnal Pendidikan Elektro.2(1) 319-326.

Putra, Danang Pradana dan Rakhmawati, Lusia (2013). Perbandingan model pembelajaran koopertif tipe numbered head together(NHT) dengan model pembelajaran kooperatif tipe student teams achievent division (STAD) terhadap hasil belajar siswa pada program diklat dasar -dasar teknik digital di SMKN 7 surabaya. Jurnal Pendidikan Elektro.2(2) 467-473

Pengaruh Kecerdasan Emosional Dan Minat Belajar Terhadap Prestasi Belajar Mata Pelajaran Kewirausahaan 